\title{
Structural robustness assessment of concrete frames considering membrane action effects
}

\author{
Wouter Botte, Klaas Adam, Robby Caspeele, Luc Taerwe \\ Ghent University, Ghent, Belgium
}

Contact: Wouter.Botte@UGent.be

\begin{abstract}
One way to increase the structural robustness is to take into account membrane action effects in beams and slabs. This membrane action generates an additional load transfer to neighbouring supports, which can considerably increase the load-carrying capacity of the member under consideration. However, the effect of membrane action on commonly used robustness indicators is still unknown. In previous contributions of the authors, a numerical model for reinforced concrete slabs and beams under large deformations was developed and validated. In this contribution, a framework is developed in order to incorporate this numerical model in the analysis of a simple concrete frame in case of column loss, in order to assess the influence of membrane action on commonly used robustness indicators.
\end{abstract}

Keywords: Robustness, membrane action, frame analysis.

\section{Introduction}

Interest in the robustness of concrete structures increased strongly after the partial collapse of the apartment building at Ronan Point (UK) in 1968. This event resulted in extensive research associated with the progressive collapse of structures. In addition, the terrorist attacks on the World Trade Centre in New York and the Pentagon in Washington in 2001 triggered a renewed interest in this research topic.

Numerous recent publications have been focusing on the concept of robustness, the definition of robustness indicators, etc. Different design strategies that increase the robustness have been identified, one of which is to provide alternative load paths. However, only limited research is available with respect to the accurate quantification and modelling of the residual bearing capacity of structural systems after the establishment of an alternative load path. In case of reinforced concrete ( $\mathrm{RC}$ ) elements, such an alternative load path can be obtained by the transition from bending behaviour to compressive or tensile membrane action.

Figure 1 shows a typical load - deflection diagram for an unrestrained RC beam as well as for a fully restrained $\mathrm{RC}$ beam.

In case no horizontal restraint is present, the beam will deflect under the applied load until a yielding plateau establishes and the slab fails either due to concrete crushing or rupture of the reinforcement. No increase in the load-carrying capacity is observed.

Considering a beam with (perfect) edge restraints against lateral displacement, compressive membrane action is induced at small deflections due to restraining the outward movement along the slab edges. This may offer a much higher 
flexural load than the maximum load predicted by Johansen's Yield Line Theory (1962), especially in case of elements with small slenderness. After the outermost flexural load has been reached in point A, the load-displacement graph shows a rapid decrease of the supported load with further increasing deflection as a result of the reduction of compressive membrane forces. Further, near point $B$, membrane forces reach the stage where they change from compression to tension. The slab's boundary restraints start to resist inward movement of the edges. It is observed that beyond point $B$ the reinforcement acts as a tensile net that enables additional load-carrying capacity under increasing deflections. The load increases for a second time until point $C$.

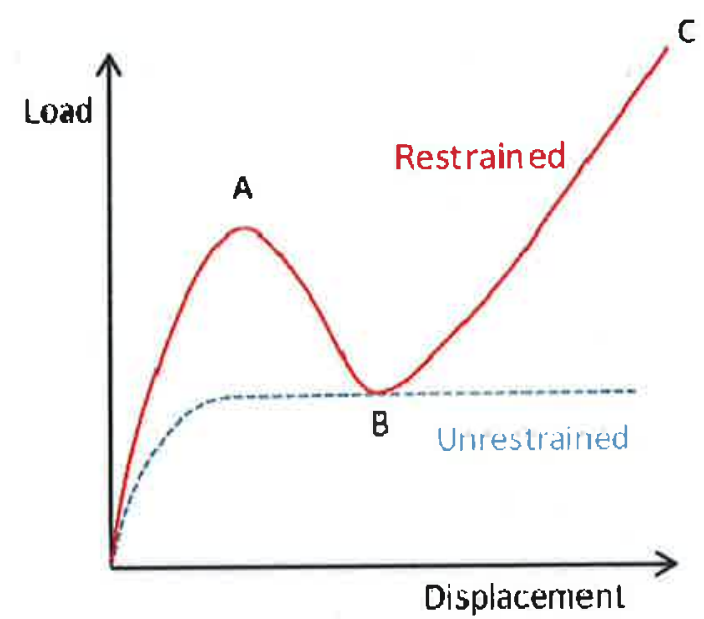

Figure 1. Schematic representation of the response curve of an unrestrained and a restrained $R C$ element under membrane action

Failure of the concrete element can either occur in the compressive membrane range (for elements with a low slenderness such as beams) or in the tensile membrane range (for elements with a high slenderness such as slabs).

In case of robustness quantification or robustnessbased design, the quantification of the capacity of the alternative load path established by the development of membrane action becomes of crucial importance. Therefore, in this contribution, a multi-level framework is developed in order to incorporate these membrane effects in the analysis of a simple concrete frame in case of sudden column loss.

\section{Multi-level framework}

The multi-level framework for the assessment of multi-storey buildings considering sudden column loss was already introduced by lzzuddin et al. [1] and illustrated for steel buildings [1] and composite steel-concrete buildings [2]. The assessment may be carried out at different levels of structural idealisation, resulting in a significant computational savings, which is the main advantage of this framework. Detailed modelling can be considered at low levels of structural idealisation, to account accurately for the nonlinear response of the structural elements (i.e. membrane behaviour), while simplified modelling can be applied at higher levels of structural idealisation.

In this contribution, such a framework is applied in case of reinforced concrete structures.

\subsection{Definition of accidental situation}

As a first step to determine the robustness of an $\mathrm{RC}$ frame with respect to column removal, the column under consideration is removed and the structure is 'divided' into two parts (Figure 2). The directly affected part (DAP) consists of the bay immediately above the removed column, where large deformations will occur. These deformations will be accompanied by membrane forces and hence a detailed analysis of this part (by means of a Finite Element (FE) analysis) will be necessary.

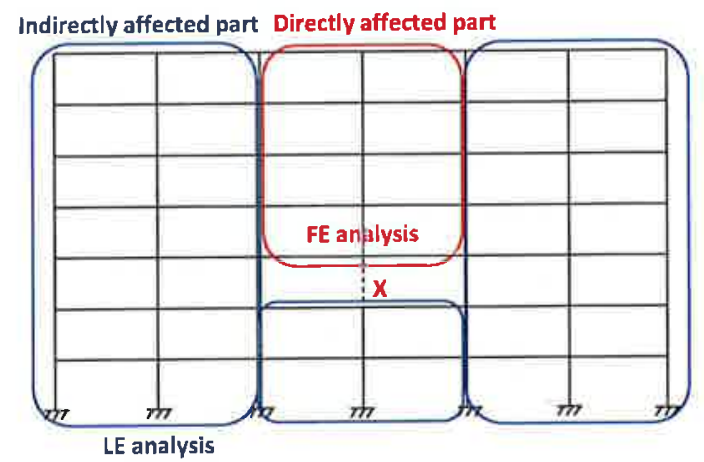

Figure 2. Definition of the accidental situation

The indirectly affected part (IAP) consists of the remaining part of the building, where less deformations are expected, hence a less detailed 
analysis of this part can be performed (e.g. a linear elastic analysis).

It should be noted that the appropriate boundary conditions for the directly affected part have to be determined, to represent the interaction with the surrounding structure.

\subsection{FE analysis of the DAP}

The second step is the analysis of the directly affected part through a nonlinear finite element calculation.

\subsubsection{Boundary conditions for the DAP}

It was indicated by Botte et al. [3] that the stiffness of neighbouring elements has an important influence on the behaviour of concrete elements subjected to large deformations. This stiffness can be derived from a linear elastic analysis of the indirectly affected part. Therefore, bending moments and horizontal forces are applied on an auxiliary frame (without the DAP) at each point where a floor from the directly affected part was removed (Figure 3). Subsequently, displacements and rotations are determined.

The horizontal deflection $\delta_{i}$ at floor $i$ caused by the membrane forces $F_{1} \ldots F_{n}$ (Figure 3 ) is in general given by:

$$
\delta_{i}=\sum_{j=1}^{n} \delta_{j i}=\sum_{j=1}^{n} \frac{F_{j}}{k_{j i}}
$$

Where $k_{\mathrm{ji}}$ is an equivalent spring constant that gives the relation between the deflection $\delta_{\mathrm{ji}}$ at floor $i$ caused by a force $F_{j}$ at floor $j$.

By rewriting equation (1), one finds:

$$
\delta_{i}=F_{i} \cdot\left(\frac{1}{k_{u}}+\sum_{\substack{j=1 \\ j \neq i}}^{n} \frac{F_{j}}{F_{i}} \cdot \frac{1}{k_{j i}}\right)
$$

And finally, the translational spring constant $K_{i}$ for floor $i$ is given by:

$$
\boldsymbol{K}_{\mathrm{i}}=\frac{F_{i}}{\delta_{i}}=\frac{1}{\frac{1}{k_{\mathrm{ii}}}+\sum_{\substack{j=1 \\ j=\mathrm{i}}}^{n} \frac{F_{j}}{F_{\mathrm{i}}} \cdot \frac{1}{k_{j \mathrm{i}}}}
$$

Note from equation (3) that the stiffness of the boundary condition at a certain floor $i$ also depends on the membrane forces $F_{j}$ at other floors, which are initially unknown. Hence an iterative approach is necessary.

One can follow the same procedure in order to calculate the rotational spring constant $\mathrm{R}_{\mathrm{i}}$ :

$$
R_{i}=\frac{M_{i}}{O_{i}}=\frac{1}{\frac{1}{r_{i i}}+\sum_{\substack{j=1 \\ j \neq i}}^{n} \frac{M_{j}}{M_{i}} \cdot \frac{1}{r_{j i}}}
$$

Note that in general the spring constant $\mathrm{r}_{\mathrm{ji}}$ is quite large. Hence the latter equation can be simplified:

$$
P_{i}=r_{i i}
$$

The spring constants obtained from equations (3) and (5) are consequently used as boundary condition in the finite element analysis of the elements in the directly affected part.

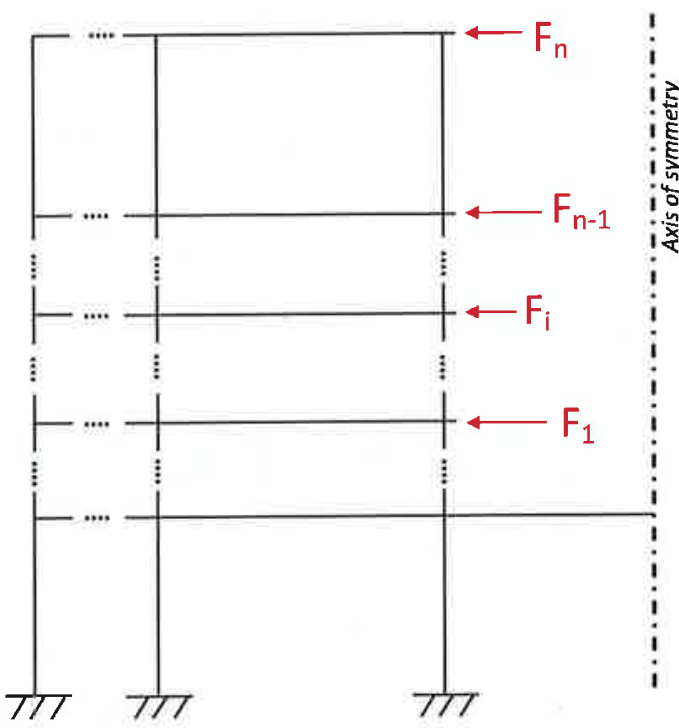

Figure 3. Indirectly affected part subjected to membrane forces 


\subsubsection{FEM model}

In the present study, an advanced finite element software (TNO Diana) is used to perform the analysis of reinforced concrete elements subjected to large deformations. As a basis, the model developed by Gouverneur [4] has been used. Additional information on this numerical model and the validation of this model can be found in [4], [5] and [6].

Geometrical nonlinearity is taken into account by a total Lagrange approach. Eight-node quadrilateral isoparametric plane stress elements (CQ16M) based on quadratic interpolation and Gauss integration are used to model the concrete elements. For reinforcement, one dimensional fully embedded bar reinforcement (truss elements) are applied with perfect bond between the reinforcement and the neighbouring concrete elements. Strains for the reinforcement are calculated based on the surrounding concrete elements.

The concrete compressive behaviour is implemented as a bi-linear stress-strain relationship considering the obtained test results on control specimens. A Hordijk tension softening model and a total strain fixed crack model is adopted for concrete in tension. For reinforcing steel, a multi-linear stress-strain relationship in accordance with laboratory testing on reference specimens is applied. Further, the strain hardening hypothesis together with the Von Mises plastic criterion was used.

Further translational and rotational springs are implemented as boundary conditions, considering the results from equation (3) and (5) (Figure 4).

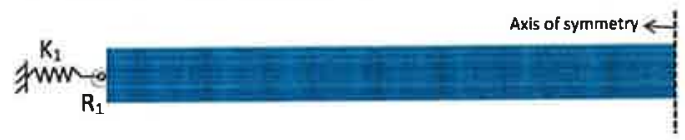

Figure 4. FE model

Finally, when the FE model is constructed, the failure load of the element and corresponding membrane forces are determined by applying a uniform load in small load steps. Note that failure of the element is governed by crushing of the concrete or rupture of the reinforcement.

\subsection{Linear elastic analysis of the IAP}

The final step is the analysis of the indirectly affected part. Therefore, the maximum load determined in the FE analysis of the DAP is applied on the IAP, together with the corresponding reaction/membrane forces. Subsequently, one should check whether the IAP is able to carry these loads. When this is the case, failure will occur in the DAP; if not, the load and corresponding membrane forces should either be reduced and failure will occur in the IAP, or a more detailed (non-linear) analysis of the failing element in the IAP should be performed.

\section{Example frame}

\subsection{General configuration}

The framework established above is illustrated by means of an example concrete frame. This frame consists of four spans of $6 \mathrm{~m}$, six floors of $3,5 \mathrm{~m}$ high and is designed as an office building according to EN 1991-1-1 [7] (Figure 5). The distance between the portals is $6 \mathrm{~m}$. The connection of the columns to the foundation is assumed to be clamped. The column and beam numbers are mentioned in Figure 5.

\begin{tabular}{|c|c|c|c|}
\hline C6 & $\begin{array}{ll}\mathrm{B} 6 & \mathrm{C} 12 \\
\end{array}$ & B12 & ${ }_{\text {C18 }}{ }^{\mathrm{B} 18}$ \\
\hline C5 & $\begin{array}{ll}85 & \\
& \text { C11 }\end{array}$ & B11 & ${ }_{C 17}{ }^{\bar{B} 17}$ \\
\hline C4 & $\begin{array}{ll}\text { B4 } & \text { C10 }\end{array}$ & $\overline{B 10}$ & $\mathrm{C}_{16}^{\mathrm{B} 16}$ \\
\hline C3 & $\mathrm{Cg}$ & B9 & $\mathrm{C} 15^{\mathrm{B} 15}$ \\
\hline$C 2$ & $\overline{B 2}$ & $B 8$ & C14 ${ }^{\mathrm{B} 14}$ \\
\hline & $\mathrm{C}$, & B7 & $\mathrm{C}_{13}{ }^{\mathrm{B} 13}$ \\
\hline
\end{tabular}

Figure 5. General overview of the frame and indication of the column and beam numbers

The vertical loads that are considered during the design consist of a permanent load $\left(G_{k}=46,5 \mathrm{kN} / \mathrm{m}\right.$, based on $\left.g_{k}=7,75 \mathrm{kN} / \mathrm{m}^{2}\right)$, a live load $\left(Q_{k 1}=18 \mathrm{kN} / \mathrm{m}\right.$, based on $q_{k}=3 \mathrm{kN} / \mathrm{m}^{2}$ [7]) and snow load $\left(Q_{k 2}=3 \mathrm{kN} / \mathrm{m}\right.$, based on the characteristic snow load for Belgium $s_{k}=0,5$ $\mathrm{kN} / \mathrm{m}^{2}$ ) on the roof. 
The design of the elements is in accordance with EN 1992-1-1 [8]. The properties of the reinforcement $\mathrm{BE} 500 \mathrm{~S}$ and concrete $\mathrm{C} 30 / 37$ are mentioned in Table 1.

Table 1. Material properties

\begin{tabular}{cccc}
\hline Concrete properties & \multicolumn{2}{c}{$\begin{array}{c}\text { Reinforcement } \\
\text { properties }\end{array}$} \\
\hline$f_{c k}$ & $30 \mathrm{MPa}$ & $f_{y}$ & $560 \mathrm{MPa}$ \\
\hline $\mathrm{f}_{\mathrm{cm}}$ & $38 \mathrm{MPa}$ & $\mathrm{f}_{\mathrm{t}}$ & $610 \mathrm{MPa}$ \\
\hline $\mathrm{E}_{\mathrm{c}}$ & $30 \mathrm{GPa}$ & $\mathrm{E}_{\mathrm{s}}$ & $210 \mathrm{GPa}$ \\
\hline
\end{tabular}

For the sake of simplicity, only one type of crosssection for the beams is considered with dimensions $350 \times 450 \mathrm{~mm}$. The top reinforcement consists of 4 bars diameter $20 \mathrm{~mm}$ and the bottom reinforcement consists of 3 bars diameter $20 \mathrm{~mm}$. It is assumed that the reinforcement is continuous over the four spans. In order to prevent shear failure, stirrups with diameter $10 \mathrm{~mm}$ are placed. Furthermore, four types of columns are used (Figure 6 - Table 2).

The concrete cover in beams and columns is considered to be $30 \mathrm{~mm}$.

Column - type 1
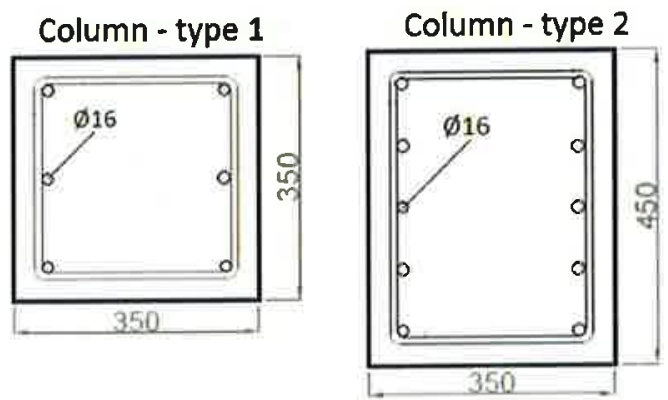

Column - type 3

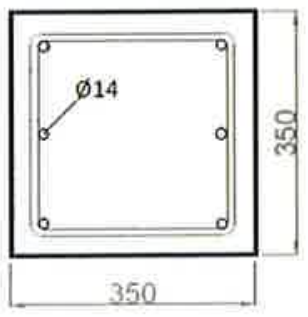

Column - type 4

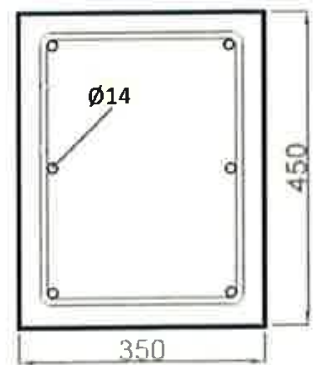

Table 2. Type of columns

\begin{tabular}{cc}
\hline Column type & Column Number \\
\hline Type 1 & $\mathrm{C} 3-\mathrm{C} 6$ \\
\hline Type 2 & $\mathrm{C} 1-\mathrm{C2}$ \\
\hline Type 3 & $\mathrm{C}$-C12 / C15-C18 \\
\hline Type 4 & $\mathrm{C} 7-\mathrm{C} 8 / \mathrm{C} 13-\mathrm{C} 14$ \\
\hline
\end{tabular}

\subsection{Accidental situation}

Subsequently, the frame is subjected to an accidental situation, i.e. the removal of the central column $\mathrm{C} 13$ on the ground floor. The combination of actions that should be considered in case of an accidental situation is (EN 1990 [9]):

$$
\begin{aligned}
& E_{u}=\sum_{j \geq 1} G_{k, j}{ }^{n}+{ }^{n} P^{m}+{ }^{m} A_{u} \\
& { }^{\prime \prime}+\left(\psi_{L, 1} \text { or } \psi_{2,1}\right) Q_{k, 1}{ }^{-}-" \sum_{i>1} \psi_{2, i} Q_{k, i}
\end{aligned}
$$

where

- $G_{k, j}$ is the dead load;

- $P$ is the prestress $(P=0$ in this case, since no prestressed elements are considered);

- $A_{d}$ is the design value of an accidental action $\left(A_{d}=0\right.$, refers to a situation after an accidental event, i.e. no consideration of an explicit accidental event);

- $a_{k, 1}$ is the live load;

- $a_{k, 1}$ are the wind and snow loads;

- $\left(\Psi_{1,1}\right.$ or $\left.\Psi_{2,1}\right)$ is a factor for the frequent and quasi-permanent value of a variable action, respectively. The frequent value $\Psi_{1,1}=0,5$ has been adopted for the leading variable load (live load). $\Psi_{2,1}=0$ for the accompanying variable actions (i.e. wind and snow loads).

Note that only a uniform load on all spans has been considered, hence no alternate loading of spans or floors has been applied.

Failure of the structure can be characterized by means of a dimensionless load factor $\lambda_{a}$, defined by:

Figure 6. Different column types (dimensions in $\mathrm{mm})$. 


$$
\lambda_{a}=E_{\text {ult }} / E_{d}
$$

where $E_{u l t}$ is the failure load determined by the analysis and $E_{d}$ is the load according to equation (6). This load factor will be used to quantify the robustness of the structure.

\subsection{Analysis}

In this example, the indirectly affected part consists of beams B1-B6 and columns C1-C12. The directly affected part consists of the 'central' part of the structure. Considering the regularity of the building, the assessment of the DAP was applied at the lowest level of idealisation, consisting of single beams (e.g. B7/B13) instead of an integrated detailed modelling of the entire DAP.

As a first step in the analysis, the stiffness of the rotational spring according to equation (5) was determined for each floor. Subsequently, FE analyses were performed for each beam, considering different stiffnesses for the translational spring, resulting in load-displacement diagrams and load-membrane force diagrams as shown in Figure 7.

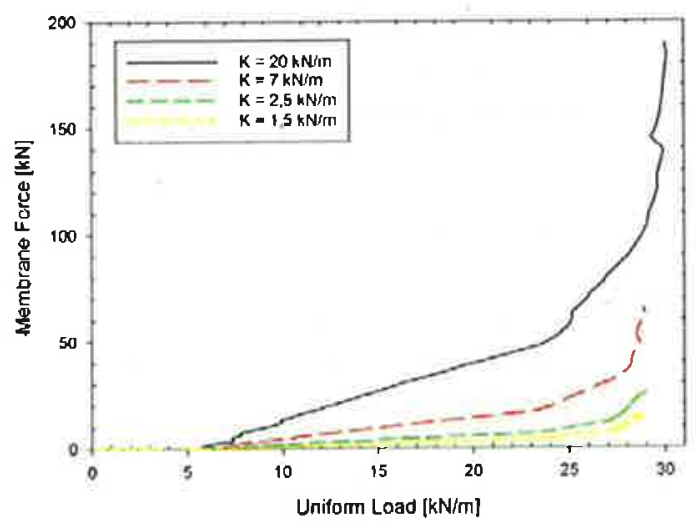

Figure 7. Membrane forces as a function of the applied load and translational stiffness $\left(1^{\text {st }}\right.$ floor)

Using these diagrams allowed to (iteratively) determine the stiffness of the horizontal boundary (according to equation (3)), the failure load of the beams in the directly affected part and finally the associated membrane forces. In case of removal of column $\mathrm{C} 13$, the ultimate load for the directly affected part was found to be about $29 \mathrm{kN} / \mathrm{m}$, resulting in rupture of the reinforcement at the $6^{\text {th }}$ floor. This failure load corresponds to a load factor $\lambda_{a}$ of 0,48 according to equation (7)

Note that all beams failed in the compressive membrane region.

In the next step, the reaction forces (i.e. membrane forces, shear forces and bending moments) and ultimate load (as found in the previous step) were applied on the indirectly affected part, in order to detect possible premature failure in that part of the structure. Failure of the beams and columns in the IAP was detected by using interaction diagrams as shown in Figure 8 for the beams and Figure 9 for the most heavily loaded columns. The normal forces and bending moments are expressed as dimensionless parameters $v$ and $\mu$ respectively, defined as follows:

$$
\begin{aligned}
& v=\frac{\Lambda}{b \cdot h \cdot f_{c k}} \\
& \mu-\frac{M}{b \cdot h^{2} \cdot f_{c k}}
\end{aligned}
$$

Where $N[\mathrm{~N}]$ and $\mathrm{M}$ [Nmm] are respectively the normal force and bending moment in the crosssection, $b$ the width of the cross-section [mm], $h$ the height of the cross-section $[\mathrm{mm}]$ and $f_{c k}$ the concrete compressive strength $\left[\mathrm{N} / \mathrm{mm}^{2}\right]$.

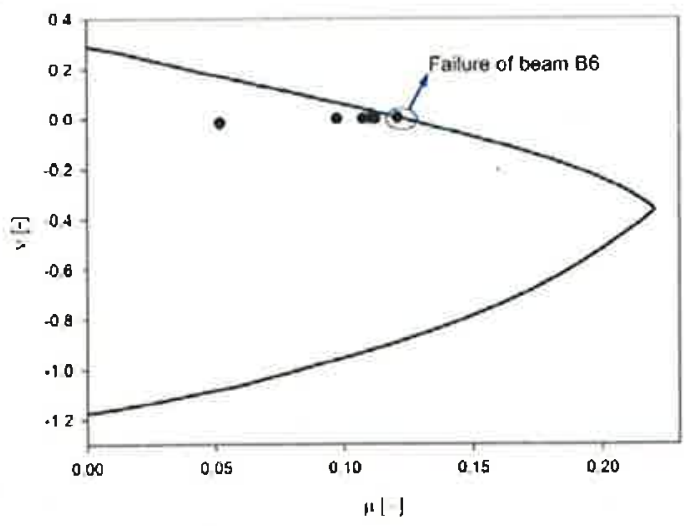

Figure 8. Interaction diagram and internal action states for the beams

As can be seen from Figure 8 , the internal action state for beam B6 is located on the acceptable boundaries in case the ultimate load (for the DAP) 
is applied. Hence, failure in the IAP will occur at the same load due to the membrane forces developed in the DAP.

It is noted that no failure of the columns will occur at this ultimate load (Figure 9).

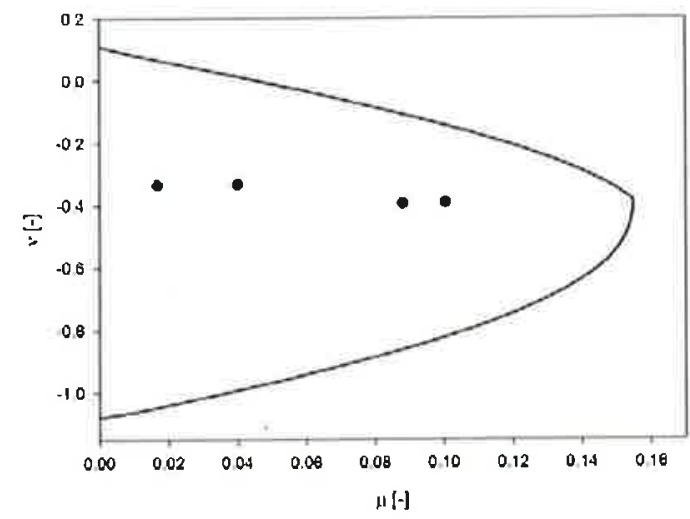

Figure 9. Interaction diagram and internal action states for the most heavily loaded columns

\subsection{Robustness quantification}

Figure 10 shows the advantage of taking into account membrane action in the robustness assessment of reinforced concrete frames. It compares the load factor $\lambda_{a}$ for different situations and calculation methods, as a function of the vertical displacement at midspan of beam $B 7$.

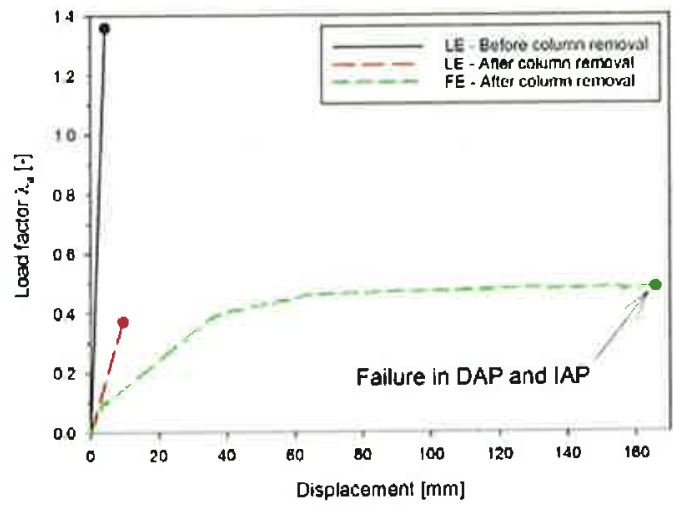

Figure 10. Load factor $\lambda_{a}$ for different situations and calculation methods as a function of the vertical displacement at midspan of beam $B 7$

It is noticed that the frame is able to carry $\lambda_{a, L E, i}=$ 1,36 times the accidental load combination as defined by equation (6), according to a linear elastic calculation and before any accidental situation occurred. In that case, failure occurs in beam $B 1$.

In case column $\mathrm{C} 13$ is removed and a linear elastic calculation is performed, the frame is able to carry $\lambda_{\mathrm{a}, \mathrm{LE}, \mathrm{d}}=0,37$ times the accidental load combination. In that case, failure will occur at beam $\mathrm{B} 7 / \mathrm{B} 13$, hence at the place where the column is removed.

As mentioned before, the load factor is reduced to 0,48 in case only the DAP is considered. However, failure will also occur in the IAP due to the membrane forces. Hence, taking into account membrane action does not only changes the failure load, but also the failure location.

The different values for the load factor as mentioned above, can be used to quantify the structural robustness. Similar to the Residual Influence Factor (RIF) ([10], [11]) used in the offshore industry, one can use the ratio of the load factor of the damaged and undamaged situation as a measure for structural robustness:

$$
\boldsymbol{R I F}=\frac{\lambda_{a, \text { damaged }}}{\lambda_{a, \text { undamrged }}}
$$

This results in a value of 0,27 in case only linear elastic calculations are considered. However, this value increases up to 0,36 in case the multi-level framework is used, which incorporates membrane action effects. Hence, an increase of $33 \%$ of the robustness indicator is observed for this particular situation!

\section{Remarks}

It should be noted that the analysis in the current contribution is:

- a static analysis, hence no dynamic effects are taken into account. These effects could be taken into account e.g. through a pseudostatic response as described in [1].

- an analysis of a 2D frame. The framework can however also be applied in 3D situations. It is noted that in that case, e.g. membrane action in slabs will contribute to the development of an alternative load path. 
- a deterministic analysis. However, as mentioned in [2], this framework can also be used in probabilistic calculations due to the computational efficiency.

Furthermore, it has be noted that one should also consider model uncertainties. However, further research efforts into this are necessary, especially due to the large deformations associated with membrane action effects.

The previously mentioned remarks are the topics of further research.

\section{Conclusions}

In this contribution, a multi-level framework for the robustness assessment of reinforced concrete frames was introduced. This framework consists of a detailed analysis of the Directly Affected Part of the frame, where large deformations are expected, and a simplified (linear elastic) analysis of the Indirectly Affected Part. This framework was consequently applied on an example frame. It was found that taking into account membrane action effects, has a beneficial effect on the Residual Influence Factor, which was used as a robustness indicator.

It should however be indicated that further research is required in order to take into account dynamic effects or in order to enable probabilitybased robustness quantification.

\section{Acknowledgements}

Wouter Botte is a Research Assistant of the FWO Research Foundation Flanders. The authors wish to thank the FWO for the financial support on the research project "Structural reliability and robustness assessment of existing structures considering membrane action effects and Bayesian updating of test information".

\section{References}

[1] Izzuddin B.A., Vlass A.G., Elghazouli A.Y., Nethercot D.A., Progressive collapse of multi-storey buildings due to sudden column loss - part i: simplified assessment framework. Engineering Structures 2008; 30(5): 1308-1318.
[2] Izzuddin B.A., Pereira M.F., Kuhlmann U., Rölle L., Vrouwenvelder T., Leira B.J., Application of probabilistic robustness framework: risk assessment of multi-storey buildings under extreme loading. Structural Engineering International 2012; 22(1):79-85

[3] Botte W., Gouverneur D., Caspeele R., Taerwe L. (2015) Influence of Design Parameters on Tensile Membrane Action in Reinforced Concrete Slabs, Structural Engineering International 2015; 25(1): 50-60

[4] Gouverneur D., Caspeele R., Taerwe L., Experimental and numerical analysis of tensile membrane action in reinforced concrete slabs in the framework of structural robustness. PhD Thesis 2014

[5] Gouverneur, Dirk, Robby Caspeele, and Luc Taerwe. "Experimental investigation of the load-displacement behaviour under catenary action in a restrained reinforced concrete slab strip." Engineering Structures 49 (2013): 1007-1016.

[6] Gouverneur, D., Caspeele, R., \& Taerwe, L. (2013). Effect of reinforcement curtailment on deflections, strain and crack development in RC slabs under catenary action. Magazine of Concrete Research, 65(22), 1336-1347.

[7] EN 1991-1-1 (2002) Eurocode 1: Actions on structures. Part 1-1: General actions Densities, self-weight, imposed loads for buildings. European Standard, CEN

[8] EN 1992-1-1 (2004) Eurocode 2: Design of concrete structures. Part 1-1: General rules and rules for buildings. European Standard, CEN

[9] EN 1990 (2002) Eurocode - Basis of structural design. European Standard, CEN

[10] Faber, M.H., Maes, M.A., Straub, D. \& Baker, J.W. 2006. On the quantification of robustness of structures, Proceedings OMAE2006, 25th Offshore Mechanics an Arctic Engineering Conference, Hamburg, Germany, June 4-9, 2006

[11] ISO 19902:2007, Petroleum and Natural Gas Industries - Fixed Steel Offshore Structures. 